\title{
Nonpalpabl Testislerde Tanısal Laparoskopi; Tek Merkez Klinik Sonuçlarımız
}

\section{Diagnostic Laparoscopy in Nonpalpable Testes; Single Center Clinical Results}

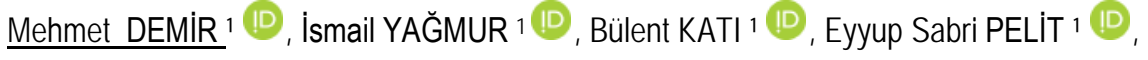 \\ Abrurrahim DUSAK $2 \mathbb{D}^{\mathbb{D}}$, Halil ÇiFTÇi 1
}

1 Harran Üniversitesi Tıp Fakültesi, Üroloji AD, Şanlıurfa, Türkiye

2 Harran Üniversitesi Tıp Fakültesi, Radyoloji AD, Şanlıurfa, Türkiye

Öz.

Amaç: Nonpalpabl testis tanı ve tedavisinde laparoskopi altın standart yöntemdir. Bu çalışmamızda nonpalpabl testis olgularında laparoskopinin tanı ve tedavideki yerini, etkinliğini ve sonuçlarını tartışmayı amaçladık.

Materyal ve Metod: Nonpalpabl testis tanısı ile laparoskopi planlanan 56 hasta çalışmaya dahil edildi. Hastaların yaşı, özgeçmişi, fizik muayene bulguları, laboratuar bulguları, ultrasonografi ve manyetik rezorans görüntüleme bulguları incelendi. Tüm hastalara genel anestezi altında tekrar muayene yapıldı. Nonpalpabl testis tanısı teyit edilen hastalara tanısal laparoskopi uygulandı. Laparoskopi bulguları, cerrahi prosedür ve komplikasyonlar değerlendirildi.

Bulgular: Çalışmaya dahil edilen 56 hastanın yaş ortalaması 15,3 22,1 yıl idi. Hastaların 28'inde sağ, 22'sinde sol, 6'sında ise her iki testis palpe edilemedi. Sekiz hastada genel anestezi sonrası yapılan muayenede testislerin palpe edilmesi üzerine laparoskopi uygulanmadan orşiopeksi yapıldı. Testisleri palpe edilemeyen 48 hastaya ise tanısal laparoskopi uygulandı. 24 hastada spermatik kordun inguinal kanala girdiği, 15 hastada testislerin intra-abdominal yerleşimli olduğu, 7 hastada kör sonlanan spermatik kord ve 2 hastada ise testis bulunmamakla birlikte müllerien yapıllar görüldü. Intra-abdominal testis bulunan hastalardan 9'una laparoskopik orşiopeksi, 6'sına ise laparoskopik orşiektomi uygulandı. Spermatik kordun inguinal kanala girdiği görülen 24 hastaya inguinal eksplorasyon yapıldı. Komplikasyon oranı $\% 4,2$ olarak bulundu.

Sonuç: Nonpalpabl testis olgularında hem tanı hem de tedavi amacıyla kullanılabilen laparoskopi, düşük komplikasyon oranları ile standart olarak önerilen ve yaygın kabul gören bir yöntemdir.

Anahtar Kelimeler: Nonpalpabl testis, Inmemiş testis, Tanısal laparoskopi

Abstract

Background: Laparoscopy is the gold standard method for the diagnosis and treatment of nonpalpable testes. In this study we reviewed the place of diagnostic laparoscopy and evaluated the results and effectiveness of laparoscopy in the diagnosis and management of nonpalpable testis.

Materials and Methods: Fifty-six patients who were scheduled for laparoscopy with a diagnosis of nonpalpable testis were included in the present study. Patients' age, history, physical examination findings, laboratory findings, ultrasonographic and magnetic resonance imaging findings were examined. All patients were re-examined under general anesthesia. Diagnostic laparoscopy was performed in the patients in whom the diagnosis of nonpalpable testis was confirmed. Laparoscopic findings, surgical procedure and complications were evaluated.

Results: The mean age of 56 patients included in the current study was 15,3 $\pm 2,1$ year. The right testicle could not be palpated in 28 patients, the left testicle could not be palpated in 22 patients, and both testicles could not be palpated in 6 of the patients. Orchiopexy was performed without laparoscopy in 8 of the patients upon palpation of the testicles during the examination performed under general anesthesia. Diagnostic laparoscopy was performed in 48 patients whose testicles could not be palpated. It was seen that the spermatic cord entered the inguinal canal in 24 patients, the testicles were located intraabdominally in 15 patients, 7 patients had a blind-ending spermatic cord, and there were no testicles but Müllerian structures in 2 patients. Laparoscopic orchiopexy was performed in 9 of the patients with intra-abdominal testicles, and laparoscopic orchiectomy was performed in 6 of these patients. Inguinal exploration was performed in 24 patients, whose spermatic cord appeared to enter the inguinal canal. The rate of complications was found to be $4.2 \%$.

Conclusions: Laparoscopy, which can be used for both diagnostic and therapeutic purposes in cases of nonpalpable testis, is the recommended standard method that is widely accepted with low complication rates.

Key words: Nonpalpable Testes, Undescended testes, Diagnostic laparoscopy

\section{Sorumlu Yazar $I$ \\ Corresponding Author}

\section{Dr. Mehmet DEMIR}

Harran Üniversitesi Tıp Fakültesi, Üroloji Anabilim Dalı,

Osmanbey Kampüsü Şanlıurfa

\section{TIf: 04143184866}

e- mail: drdemir02@gmail.com

Geliş tarihi / Received: 12.11.2019

Kabul tarihi / Accepted: 25.02 .2020

DOI: $10.35440 /$ hutfd. 645863 


\section{Giriş}

Inmemiş testis zamanında tedavi edilmezse spermogenetik fonksiyon sekeli bırakan yaygın bir genitoüriner bozukluktur. Tüm çocukların yaklaşık \%3'ünde görülür (1). Bunların çoğunluğu muayenede palpe edilebilirken, \%20\%30'u Nonpalpabl Testis (NPT) şeklinde karşımıza çıkmaktadır (2). NPT'lerin \%20-25'i batın içinde, yaklaşık $\% 60$ ' inguinal kanalda bulunur. Bunların bazıları intraüterin dönemde atrofiye gitmektedir (3). NPT tanısında fizik muayene en önemli basamak olup, Ultrasonoğrafi (US) ve Magnetik Rezorans Görüntülenemin (MRI) tanısal duyarlılığı düşük kabul edilmektedir (4). NPT'de görüntülemenin rolü tartışmalıdır. Radyolojik görüntüleme NPT'li olgularda testisin lokalize edilmesi ve cerrahi planlama için tercih edilmektedir. Bununla birlikte, bazı cerrahlar radyolojik görüntüleme yöntemlerini kullanmadan laparoskopik taramayı önermektedir. Bu yaklaşımın arkasında, radyolojik görüntüleme yöntemlerinin, rutinde cerrahi yakalaşımı değiştirmediği görüşü bulunmaktadır $(5,6)$. NPT'li olgularda, anorşi tanısının radyoloji görüntüleme yöntemleri ile konması oldukça düşük olup tanı için laparoskopi gereklilik göstermektedir. Intra-abdominal testisin radyolojik görüntüleme yöntemleri ile saptanması tanıyı değiştirmektedir ancak bu durum oldukça düşük görülmekte olup \%2'lerde bir oran bildirilmiştir (7). Poliklinik şartlarında palpe edilemeyen testislerin \%18-34 ü anestezi altında yapılan muayenede palpe edilebilmektedir (8.9). Obez hastalarda testis muayenesi normalden daha zor olduğundan bu hastalarda anestezi altında muayene daha fazla önem arz etmektedir(10). NPT'de tanısal laporoskopiyi ilk olarak 1976 yılında Cortesi ve arkadaşları kullanmış olup (11), laparoskopik orşiopeksi ise ilk kez 1992 yılında Jordon ve arkadaşları tarafından uygulanmıştır. Yaklaşık 30 yı önce uygulanan bu yöntem günümüzde NPT tanı ve tedavisinde altın standart tedavi yöntemi olarak kabul edilmektedir $(12,13)$. NPT testis tespit edilen hastalarda amaç; testis olup olmadığını doğrulamak, uygun testislerde orşiopeksi yapmak, orşiopeksi yapılamayacak olanlarda testis ve eklerini çıkarmaktır.

\section{Materyal ve Metod}

01.01. 2014 ile 01.08. 2019 tarihleri arasında üroloji kliniğinde NPT tanısı ile laparoskopi planlanan tüm yaş grubundan 56 hasta çalışmaya dahil edildi. Dışlanma kriterimiz yoktu, fizik muayenede testis palpe edilemeyen tüm hastalar çalışmaya dahil edildi. Çalışma için Harran Üniversitesi Tıp Fakültesi Etik Kurulu'ndan etik kurul onayı alındı (28/08/2019-E.35562). Hastaların dosyaları geriye dönük incelendi. Hastaların yaşı, özgeçmişi, fizik muayene bulguları, laboratuar bulguları, US ve MRI bulguları, ameliyat raporları incelenerek kayıt edildi. 18 yaşından büyük olan hastaların spermiogramları ve testis tümör makkerları incelendi. Bilateral NPT tespit edilenlerden perioperatif periferik kanda kromozom analizi çalışıldı.
Cerrahi teknik: Tüm hastalar genel anestezi altında tekrar muayene edilerek NPT tanısı teyit edildi. Anestezi altında yapılan muayenede, testis palpe edilen hastalarda laparoskopi yapılmadan inguinal orşiopeksi yapıldı. Muayenede testis saptanmayan hastalara tanısal laparoskopi yapıldı. Tüm hastalara foley sonda ve nazogastrik sonda takıldı. Trendelenburg pozisyonuna alındı. Göbek üstü bir kesi yapılarak Veress iğnesi ile karın içerisine girildi ve 10$12 \mathrm{mmHg}$ basıncında pnömoperitoneum oluşturuldu. Ardından 5 veya 10 mm'lik bir trokar içerisinden 30 derecelik teleskop(Karl Storz®) ile karın boşluğuna girildi. Karın içerisi kontrol edildikten sonra teleskop pelvik bölgeye yönlendirilerek testisin yeri kontrol edildi. Testis yoksa vas deferens varlığı, spermatik kordun inguinal kanaldan girip girmediği veya kör sonlanan spermatik kord varlığı kontrol edildi. Kör sonlanan spermatik kord tespit edilenlerde işlem sonlandırıldı. Spermatik kordun inguinal kanaldan girdiği görülen hastalarda laparoskopi sonlandırılarak inguinal eksplorasyon yapıldı. Intra-abdominal testis tespit edilen hastalarda midklaviküler hat üzerinden sağ ve sol alt kadrana iki adet 5 mm'lik trokar konuldu. Testis belirlendikten sonra spermatik damarlar, vaz deferens, gubernakulum ve testis, künt ve keskin diseksiyonlarla serbestleştirildi. Hastaların yaşına, testisin inguinal kanala uzaklığına ve testis volümüne göre orşiopeksi veya orşiektomi planlandı. Yeterli uzunluk sağlandıktan sonra testis ve elemanları inguinal kanal açıksa buradan, açık değilse internal inguinal halkanın medialinden oluşturulan yeni kanaldan geçirildi. Skrotuma bir kesi yapıldı. Bu kesiden 5 mm'lik bir trokar geçirildi ve inguinal kanala doğru ilerletildi. Trokarın içerisinden bir pensle girilip testis ve elemanları skrotuma çekildi. Testis dartosa tespit edildi ve dartos altında hazırlanan poşa yerleştirildi. Orşiektomi yapılmasına karar verilenlerde vaz deferens ve spermatik damarlar klipslenerek testis dışarıya alındı. Alınan spesmenler patolojik incelemeye gönderildi.

\section{Bulgular}

Çalışmaya dahil edilen 56 hastanın yaş ortalaması 15,3 $\pm 2,1$ yıl idi. Hastaların 28 'inde sağ, 22'sinde sol, 6 'sinde bilateral NPT mevcuttu (Tablo 1).

Tablo 1. Tanısal laparoskopi yapılan hastalar

\begin{tabular}{l|l|l|l}
\hline Tanısal laparoskopi & Sağ & Sol & Bilateral \\
\hline $\mathrm{n}: 56$ & $\mathrm{n}: 28(\% 50)$ & $\mathrm{n}: 22(\% 39,3)$ & $\mathrm{n}: 6(\% 10,7)$ \\
\hline
\end{tabular}

Genel anestezi verilen 56 hastanın 8'inde muayenede testis palpe edildi ve inguinal orşiopeksi yapıldı. Testisleri palpe edilemeyen 48 hastaya ise tanısal laparoskopi uygulandı. Tanısal laparoskopi sırasında $24(\% 50)$ hastada spermatik kordun inguinal kanala girdiği, $15(\% 31,2)$ hastada testislerin intra-abdominal yerleşimli olduğu, $7(\% 14,6)$ hastada kör sonlanan spermatik kord ve $2(\% 4,2)$ hastada ise testis bulunmamakla birlikte müllerien yapılar görüldü 
(Şekil 1). Spermatik kordun inguinal kanaldan girdiği tespit edilen 24 hastaya inguinal eksplorasyon yapıldı. Bunların 19 'unda nubbin testis tespit edildi ve orşiektomi yapıldı. Innguinal eksplorasyon yapılan 3 hastada testiküler ağenezi tespit edildi. İki hasta da ise inguinal testis bulunup orşiopeksi yapıldı. Batın içinde testis bulunan 15 hastanın 7'sine laparoskopik orşiopeksi, 2'sine Fowler-Stephens orşiopeksi (14), 6'sına ise laparoskopik orşiektomi yapıldı. Tanısal laparoskopide kör sonlanan spermatik kord görülen hastalar ile müllerien yapılar görülen hastalarda işlem sonlandırıldı. Orşiektomi yapılan bütün hastaların spesmenleri patolojik incelemeye gönderildi. Bu spesmenlerin incelemesinde maliğnite rapor edilmedi.

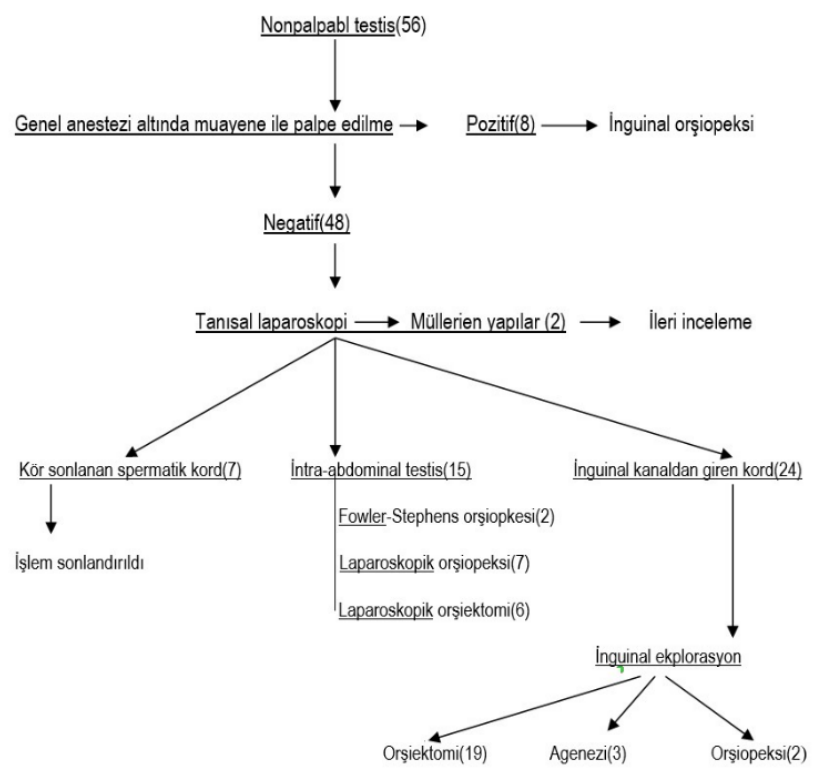

Şekil 1. Nonpalpabl testis tespit edilen hastalarda uyguladığımız algoritma

Komplikasyon oranımız \%4,2(2/48) olarak bulunmuştur. Olgularımızda organ yaralanması görülmemiş, bir olguda preperitoneal $\mathrm{CO} 2$ insuflasyonu, bir olguda ise inguinal ve skrotal bölgede cilt altı amfizemi oluştu.

\section{Tartışma}

NPT grubunu inta-andominal yerleşimli testisler, inguinal yerleşimli atrofik testisler ve agenetik testisler oluşturmaktadır(3). Fizik muayene, palpabl ve NPT grubunu belirlemede en önemli basamak olsa da testis lokalizasyonunu belirlemek için ek yöntemlere intiyaç duyulmaktadır. NPT tanısında en sık kullanılan görüntüleme yöntemi US olup özgüllüğü \%78, duyarlılı̆ı̆ \%45'dir (15). MRI ve Bilgisayarlı tomografinin(BT)'nin özgüllüğü ve duyarlıı̆ı daha yüksektir ancak sedasyon intiyacı ve radyasyona maruz kalma riskleri nedeniyle kullanımları sınırıdır $(16,17)$. Bu nedenle herhangi bir görüntüleme yöntemine başvurulmadan tedavi olanağı da sunabilen laparoskopinin ilk tercih kullanılması savunulmuştur $(5,6)$.
Karşı görüşte olan bazı yazarlar ise laparoskopi yapmadan önce skrotal ve inguinal eksplorasyon önermektedirler. Bunun sebebini ise vakaların çok büyük kısmının inguinal veya skrotal vanishing testis olduğuna bağlamaktadırlar. Bae ve arkadaşları yaptıkları çalışmada intra-abdominal peeping testislere inguinal kesi ile ulaşılabildiğini, yalnızca 3 hastada laparoskopiye intiyaç duyduklarını bildirmişlerdir (19). Benzer şekilde Snodgrass ve arkadaşlarının yaptığı çalışmada hastaların sadece \%23'ünde laparoskopiye intiyaç duyulduğu gösterilmiştir (20). Görüntüleme yöntemlerinin özgüllüğü ve duyarlılığının düşük olması, sedasyon intiyacı ve radyasyona maruziyet nedeniyle, aynı zamanda bu hastalarda poliorşidizm de olabileceğinden işleme tanısal laparoskopi ile başlanılması gerektiğini düşünmekteyiz. Mevcut literatür NPT'li hastalarda genel anestezi altında tekrar fizik muayene yapılmasını önermektedir. Yapılan çaIş̧malarda poliklinik şartlarında palpe edilemeyip genel anestezi altında palpe edilen testislerin oranı \%18-34 olarak bildirilmiştir $(8,9)$. Çalışmamızda NPT tanılı 56 hastanın $\% 14,2(8)$ 'sinde anestezi altında testis palpe edildiğinden laparoskopi yapılmadan orşiopeksi yapılmıştır. Bu öneri doğrultusunda hastalara yapılacak gereksiz cerrahi girişimin önüne geçilmiştir.

NPT'lerde, vakaların \%33-76'sında spermatik kordun inguinal kanala girdiği, \%15-52'sinde intara-abdominal testis, \%9-22'sinde ise kör sonlanan spermatik kord görülebilir (21). Anwar ve arkadaşlarının yaptığı çalışmada da benzer oranlar bildirilmiştir (1). Çalışmamızda hastaların $\% 50(24)$ 'sinde spermatik kordun inguinal kanala girdiği, $\% 31,2(15)$ 'sinde testislerin intra-abdominal yerleşimli olduğu, $\% 14,6(7)$ 'sında kör sonlanan spermatik kord ve $\% 4,2(2)$ 'sinde ise testis bulunmamakla birlikte müllerien yapılar görüldü. Bulgularımız literatür ile uyumlu idi.

Daha önce yapılan çalışmalarda, spermatik kordun kör sonlandığı hastalarda laparoskopinin sonladırılarak ek girişimde bulunulmadığı bildirilmiştir $(1,22)$. İnternal ringin üzerinde sonlanan spermatik kordun skrotal nubbin testis ile ilişkili olabileceği de unutulmamalıdır. Bununla ilgili Snodgrass ve arkadaşları nubbin testis ile ilişkili kör sonlanan spermatik kord bulunan 6 vaka bildirmişlerdir (23). ÇaIışmamızda kör sonlanan spermatik kord tespit edilen 7 hastada laparoskopiyi sonlandırarak ek girişimde bulunmadık.

Spermatik kordun inguinal kanala girdiği görülen 24 hastada inguinal eksplorasyon yapıldı. Bu hastalardan testis volümü iyi olan 2 hastaya orşiopeksi yapıldı. Bu 2 hastanın ortak özelliği body mass indexin ve pubik yağ dokusunun fazla olmasıydı. Bu nedenle fizik muayene testisin palpe edilemediğini düşünüyoruz.

Nubbin testis tespit edilen 19 hastaya ise orşiektomi yapıldı. Nubbin testis klinik olarak kabul edilmeyen, patolojik inceleme sonrası normal testis dokusu tanımlanamayan bir durumdur (24). Bu, spermatik kordonun sonunda bir testis 
kalıntıSı, nodül veya testis/paratestiküler dokunun iplikçikliğini içerir. Testis regresyon sendromlu olarak da adlandırılan bu hastaların yönetimi tartışmalıdır. Tartışmasının ana nedeni, farklı çalışmalarda germ hücrelerinin ve seminifer tubullerin görülmesidir. Bu durumda maliğnite riskinin artabileceği düşünülmektedir $(21,25,26)$. Her ne kadar bu malignite riski tartışmalı kalsa da, nubbin testisde germ hücreleri ve seminifer tübül bulunabileceğinden ve sonraki takiplerinin zor olacağını düşündüğümüzden nubbin testislerin çıkarılmasını önermekteyiz.

Orşiopeksinin 2 yaşından önce yapılması durumunda fertiliteye katkıda bulunacağı bilinmektedir (27). Yine T. Walsh ve arkadaşlarının yaptığı meta-analizde postpubertal orşiopeksi yapılan olgularda testis kanseri gelişme riskinin daha erken yaşta yapılanlara göre 3,5 kat daha fazla olduğu gösterilmiştir (28). Puberteden sonra başvuran olgularda izlem, orşiopeksi veya orşiektomiyi tercih etmek güç bir karardır. Çalışmamızda 18 yaş üzeri 14 hasta bulunmaktaydı. Bu hastaların 1'inde bilateral inmemiş testis, 2 'sinde ise diğer testisin atrofik olması nedeniyle orşiopeksi yapılmıştır. Postpubertal dönemde cerrahi mudahalenin biçimini (orşiektomi - orşiopeksi) belirlemede, inmemiş olan testisin androjen üretme kapasitesi, özellikle soliter testisi olan olgularda ve bilateral inmemiş testislerde önem arz etmektedir. Bu durumlarda kişiye özgü tedavi biçimi belirlenmesi gerektiğini düşünmekteyiz.

NPT'de tanısal laparoskopi sırasında cerrahi komplikasyon nadiren görülmektedir. Veress iğnesi girişi nedeni ile preperitoneal insuflasyon veya iğne yada trokar girişleri sırasında damar veya bağırsak yaralanmaları, hiperkarbi, gaz embolisi, aritmi ve arrest görülebilir $(29,30)$. Birçok çalışmada belirtildiği gibi morbidite, hastanede kalış süresi ve komplikasyon oranları açık cerrahiye göre daha iyidir $(31,32)$. Komplikasyon oranımız \%4,2(2/48) olarak bulunmuş olup literatür ile uyumludur.

Sonuç: NPT olgularında hem tanı hem de tedavi amacıyla kullanilabilen laparoskopi, standart olarak önerilen ve yaygın kabul gören bir yöntemdir. Laparoskopi testis lokalizasyonu ve kalitesine göre çeşitli tedavi alternatifleri sunmaktadır. Tanı ve tedavideki yüksek başarı oranlarının yanı sıra laparoskopi ile sağlanan kozmetik sonuçlar ve kısa yatış süreleri, düşük komplikasyon oranları bu tekniğin diğer üstünlükleri olarak görülmektedir.

\section{Etik Onam: Çalışma için Harran Üniversitesi Tıp Fakültesi Etik Kurulu'ndan etik onam alındı (28/08/2019-E.35562).}

\section{Kaynaklar}

1. Anwar AZM, Fathelbab TK, Abdelhamid AM, Galal EM, Ali MM Tawfiek ER. Initial laparoscopy and optimized approach for unilateral nonpalpable testis: review of 8-year single-center experience. Int Urol and Nephrol.2018; 50(12):2139-44.

2. Perez-Brayfield M, Kirsch AJ, Baseman AG. Pediatric Cryptorchidism Surgery.Medscape. Available from http://www.emedicine.medscape.com/article/1017420-overview\#4. [Updated: Sep 30, 2019].

3. Başaklar C. Inmemiş Testis. Bebek ve Çocukların Cerrahi ve Ürolojik
Hastalıkları. 2. Cilt. Ankara: Palme Yayıncılık, 2006;1717-52.

4. Elder JS. Ultrasonography is unnecessary in evaluating boys with a nonpalpable testis. Pediatrics. 2002;110(4):748-51.

5. Cortesi N, Ferrari P, Zambarda E, Manenti A, Baldini A, Morano FP. Diagnosis of bilateral abdominal cryptorchidism by laparoscopy. Endoscopy. 1976;8(1):33-4.

6. Tennenbaum SY, Lerner SE, McAleer IM, Packer MG, Scherz HC, Kaplan GW. Preoperative laparoscopic localization of the nonpalpable testis: A critical analysis of a 10-year experience. J Urol 1994;151(3):732-4.

7. Baillie CT, Fearns G, Kitteringham L, Turnock RR. Management of the impalpable testis: The role of laparoscopy. Arch Dis Child, 1998;79(5):419-22.

8. Jared D. Christensen, MD, and Vikram S. Dogra, MD. The Undescended Testis. Semin Ultrasound CT MRI, 2007; 28:307-16.

9. Fowler R Jr, Stephens FD. The role of testicular vascular anatomy in the salvage of high undescended testes. Aust N Zeal J Surg, 1959; 29: 92-106

10. Cisek LJ, Peters CA, Atala A, Bauer SB, Diamond DA, Retik AB. Current findings in diagnostic laparoscopic evaluation of the nonpalpable testis. J Urol, 1998; 160:1145-49.

11. Zakaria OM, Hokka E, El Kadi KE, Al Buali WH, Zakaria HM, Daoud MY et al. Examination under anesthesia for management of impalpable undescended testis: A traditional technique revisited. World J Surg, 2013; 37(5):1125-29.

12. Breyer BN, DiSandro M, Baskin LS, Hsieh MH. Obesity does not decrease the accuracy of testicular examination in anesthetized boys with cryptorchidism. J Urol, 2009; 181(2):830 4.

13. Vikraman J, Hutson JM, Li R, Thorup J. The undescended testis: Clinical management and scientific advances. Semin Pediatr Surg. 2016; 25(4):241-8.

14. Aykut Kefi, Elnur Mammadov. Diagnostic Management of Undescended Testis. Turk Urol Sem, 2010; 1: 60-2.

15. Tasian GE, Copp HL. Diagnostic performance of ultrasound in nonpalpable cryptorchidism: a systematic review and meta-analysis. Pediatrics, 2011; 127(1):119-28.

16. Kantarci M, Doganay S, Yalcin A, Aksoy Y, Yılmaz B et al. Diagnostic performance of diffusion-weighted MRI in the detection of nonpalpable undescended testes: comparison with conventional MRI and surgical findings. AJR Am J Roentgenol, 2010; 195(4):W268-W273.

17. Smith-Bindman R, Lipson J, Marcus R,Kim KP, Mahesh M, Gould $\mathrm{R}$, et al. Radiation dose associated with common computed tomography examinations and the associated lifetime attributable risk of cancer. Arch Intern Med, 2009;169(22):2078-86.

18. Kolon TF, Herndon A, Baker LA, Baskin LS, Baxter CG, Cheng EY et al. Evaluation and Treatment of Cryptorchidism: AUA Guideline. J urol, 2014; 192(2):337-345.

19. Bae KH, Park JS, Jung HJ, Shin HS. Inguinal approach for the management of unilateral non-palpable testis: is diagnostic laparoscopy necessary? J Pediatr Urol, 2014; 10(2):233-6.

20. Snodgrass WT, Yucel S, Ziada A. Scrotal exploration for unilateral nonpalpable testis. J Urol, 2007; 178(4 Pt 2):1718-21.

21.Ueda N, Shiroyanagi Y, Suzuki H, Kim WJ, Yamazaki Y, Tanaka Y. The value of finding a closed internal ring on laparoscopy in unilateral nonpalpable testis. J Pediatr Surg, 2013; 48:542-546.

22. Yamazaki Y, Suzuki M, Shiroyanagi Y, Matsunol D, Tanaka Y. Scrotal nubbins associated with blind-ending spermatic vessels and a normal vas deferens on laparoscopy. Int J Urol, 2009; 16:902-4.

23. Snodgrass WT, Chen K, Harrison C.Initial scrotal incision for unilateral nonpalpable testis. J Urol, 2004; 172:1742-45.

24. Nataraja RM, Asher CM, Nash R, Murphy FL. Is routine excision of testicular remnants in testicular regression syndrome indicated? J Pediatr Urol. 2015;11(3):151.e1-5.

25. Storm D, Redden T, Aguiar M, Wilkerson M, Jordan G, Sumfest J. Histologic Evaluation of the Testicular Remnant Associated with the Va- 
nishing Testes Syndrome: Is Surgical Management Necessary? Urology, 2007;70(6):1204-6.

26. Hegarty PK, Mushtaq I, Sebire NJ. Natural history of testicular regression syndrome and consequences for clinical management," Journal of Pediatric Urology, 2007;3(3):206-8.

27. Rogers E, Teahan S, Gallagher H, Butler MR, Grainger R, McDermott TE, et al. The role of orchiectomy in the management of postpubertal cryptorchidism. The Journal of urology. 1998; Mar;159(3):851-4. 28. Walsh TJ, Dall'Era MA, Croughan MS, Carroll PR, Turek PJ. Prepubertal orchiopexy for cryptorchidism may be associated with lower risk of testicular cancer. J Urol. 2007;178(4 Pt 1):1440- 6. 